\title{
Recursos para una historia de las culturas musicales: la Revista de la Asociación Wagneriana de Buenos Aires (1914-1926)
}

\section{María Josefina Irurzun}

Universidad Nacional del Centro de la Provincia de Buenos Aires - Consejo Nacional de Investigaciones Científicas y Técnicas, Buenos Aires, Argentina joseirurzun@hotmail.com

\section{Resumen}

El objetivo general del presente trabajo es complejizar los abordajes tradicionales de las revistas de música para concebirlas como dispositivos y prácticas de acción social que caracterizan a las culturas musicales, así como interpelan diversas esferas de la opinión pública. Para ello, se analiza el caso de la Revista de la Asociación Wagneriana de Buenos Aires (publicada por la Asociación homónima), a partir de la periodización de los momentos vitales o editoriales de la misma, atendiendo a la pluralidad de contextos y los aspectos relacionados con ellos, su forma de organización colectiva como espacio de enunciación, sus modos de ser, estilo, recursos, etc. Se argumenta que, si bien la dependencia de la publicación respecto a la entidad condicionó su forma y contenido, operó también como una institución en sí misma ("una tribuna de arte y cultura"). Por último, se señalan las múltiples posibilidades de indagación de las revistas de música (con frecuencia concebidas como "manifestaciones" de procesos que ocurren por fuera de ellas), la dinámica de sus cambios e intervenciones y las distintas significaciones -otorgadas a través del tiempo-, que las convierten también en revistas culturales.

Palabras clave: revistas de música, historia cultural, Asociación Wagneriana, Buenos Aires, inicios siglo XX 


\title{
Recursos para uma história das culturas musicais: a Revista de la Asociación Wagneriana de Buenos Aires (1914-1926)
}

\section{Resumo}

O objetivo geral do presente trabalho é complexificar as abordagens tradicionais das revistas de música para concebê-las como dispositivos e práticas de ação social que caracterizam as culturas musicais, assim como interpelam diversas esferas de opinião pública. Para tal, analisa-se o caso da Revista de la Asociación Wagneriana de Buenos Aires (publicada pela associação homónima), a partir da periodização dos momentos vitais ou editoriais da mesma, atendendo à pluralidade de contextos e aspectos relacionados com eles, sua forma de organização coletiva como espaço de enunciação, seus modos de ser, estilo, recursos, etc. Argumenta-se que, embora a dependência da revista em relação à entidade condicionou a sua forma e conteúdo, operou também como uma instituição em si mesma ("uma tribuna de arte e cultura"). Por último, assinala-se a dificuldade inerente à indagação das revistas de música (com frequência concebidas como "manifestações" de processos que ocorrem por fora delas), a dinâmica de suas mudanças e intervenções e as diferentes significações -outorgadas através do tempo- que as convertem também em revistas culturais.

Palavras-chave: revistas de música, história cultural, Asocación Wagneriana, Buenos Aires, início do século XX

\section{Resources for a History of Musical Cultures: The Revista de la Asociación Wagneriana de Buenos Aires (1914-1926)}

\begin{abstract}
The main objective of this paper is to rethink traditional approaches by music magazines and conceive of them as social action devices and practices that gave distinctive characteristics to musical cultures and took place in different spheres of public opinion. The analysis is based on the Revista de la Asociación Wagneriana de Buenos Aires (published by the association of the same name), starting from the periodization of its vital or editorial phases, taking into account the plurality of contexts and the aspects related to them, their collective organization as a space of enunciation, their style, resources, etc. It was found that, while the institutional dependency of the publication conditioned its form and content, it also operated as an entity in itself ("a forum for art and culture"). Finally, attention is drawn to
\end{abstract}


the multiple possibilities of researching music journals (often conceived as "manifestations" of processes occurring outside them), the dynamics of their changes and interventions, and the different meanings granted through time-, that turn them into cultural magazines.

Keywords: Music magazines, cultural history, Asociación Wagneriana, Buenos Aires, early 20th century

\section{Introducción}

En Argentina, el interés por el estudio (académico, periodístico, aficionado) de las revistas culturales, artísticas y literarias se ha visto resignificado por las tendencias de pensamiento, el "tono vital” o el carácter de época y las preocupaciones delimitadas por cada presente histórico. A finales del siglo XIX, la voluntad de reseñar y recopilar las diferentes producciones gráficas existentes hasta ese momento, estuvieron teñidas por la necesidad de marcar la falta de profesionalización del campo literario. Para Ernesto Quesada, por ejemplo, esta circunstancia -la inexistencia de editores, "hombres de letras que vivan de su pluma y de su saber" (1893, p. 122), y de un público lector interesado y competente- se explicaba por el escaso desarrollo de las revistas frente a la preponderancia de la prensa diaria. El crecimiento de las primeras -como obras colectivas abiertas-, traería, en su opinión, la posibilidad de generar un gusto literario novedoso y crear "verdadera vida intelectual" (Quesada, 1893, p. 141).

Durante la primera mitad del siglo XX y podríamos decir hasta la publicación del libro de Lafleur, Provenzano y Alonso (2006 [1967]) la inquietud por organizar y periodizar una historia de la literatura argentina, de acuerdo a criterios variados y en algunos casos imprecisos, marcó profundamente el estudio de la revistas (Croce, 2006). En este sentido, fuera para indicar la consagración de un autor, de un movimiento cultural o una tendencia ideológica - al decir de Beatriz Sarlo (1992, p. 10), siguiendo los intereses de un historiador de la cultura de entonces- la revista se concebía como manifestación del fenómeno cultural que se pretendía analizar (Louis, 2014).

En las últimas décadas del siglo XX y comienzos del XXI, en base a los aportes de la historia del arte, la sociología de la cultura y otras disciplinas, así como de libreros, coleccionistas y editores (que en muchos casos impulsaron la edición de facsimilares y símil tipográficos de revistas inaccesibles o poco exploradas), la mirada sobre las publicaciones se ha visto renovada (Eujanián, 1999; Girbal-Blacha, y Quattrochi-Wilson,1999; 
Tarcus, 2007; Pittaluga et al. 2007; Rogers, 2008; Corrado, 2010; Mansilla, 2010, entre otros). Además de considerar las posibilidades casi infinitas de abordaje de las revistas, se proponen nuevas preguntas que intentan desplazar el interés instrumental: se trata de indagar acerca de cómo las publicaciones adquieren una identidad propia, es decir, pensarlas como objetos autónomos y reflexionar en torno a su naturaleza (Artundo, 2010, p. 8; Louis, 2014). Al respecto, puede advertirse que esta preocupación por la singularidad y la identidad de una revista, responde a las preguntas de nuestro presente histórico. Si durante el siglo XIX y la primera mitad del XX, la inquietud fundamental de los intelectuales (sobre todo aquellos abocados al problema de la nación) fue cómo construir "la identidad", mantenerla sólida y estable (Heffes, 2012), hoy concebimos la identidad como un proceso permanente de reconstrucción, como algo dinámico y plural que transmuta de acuerdo a la interacción con "otro" diferente. Ante un presente que se revela voraz y efímero, el énfasis puesto en la preservación (patrimonio) ha adquirido una relevancia sin precedentes. El desarrollo de la tecnología informática, la producción de revistas que abandonan el soporte material (por variadas razones) y la preocupación por la digitalización de documentos antiguos, retratan la inseguridad vivida ante la transformación constante de las sociedades actuales.

Las dificultades relacionadas con la indagación de las revistas, la dinámica de sus cambios, y de las distintas significaciones -otorgadas a través del tiempo- son numerosas (Delgado, 2014). Más allá de la inevitable pérdida de sus auras (Sarlo, 1992, p. 9), que son siempre contemporáneas a su momento histórico, puede pensarse a las revistas como objetos semióforos, es decir, investidos de significaciones (Pomian, 2010). En esta línea, uno de los desafíos es concebirlas como dispositivos colectivos en acción que fijan determinadas posiciones en sus presentes históricos, y, más allá de la sedimentación de significados que acumulan, como documentos históricos al mismo tiempo.

En este trabajo se estudian los primeros momentos vitales o períodos editoriales de una revista en particular: la Revista de la Asociación Wagneriana de Buenos Aires (publicada por la Asociación homónima porteña), ${ }^{1}$ atendiendo a la pluralidad de contextos y los aspectos relacionados con ellos, su forma de organización colectiva como espacio de enunciación, al

\footnotetext{
${ }^{1}$ Existen estudios centrados en algunos aspectos de la Asociación Wagneriana, como el de Mansilla (2004), en el que la autora reseña algunos datos sobre la publicación, y Dillon, (2007) quien presenta una cronología general de las actividades públicas de la entidad musical. Para abordajes conjuntos sobre la Asociación y la Revista, cf. Irurzun (2015a y 2017b).
} 
mismo tiempo que se historizan sus modos de ser, estilo, recursos, etc. ${ }^{2} \mathrm{El}$ objetivo general es complejizar abordajes tradicionales de las revistas de música para pensarlas como dispositivos y prácticas de acción social que otorgaron características distintivas a las culturas musicales e interpelaron diversas esferas de opinión pública. En este sentido, la categoría "cultura/s musical/es" propone comprender las dimensiones socio-culturales de la música: los espacios formales o informales donde ocurre o se piensa la música, los actores sociales involucrados, sus prácticas, las ideas y los saberes que derivan, a su vez, en normas, costumbres, estilos propios y específicos de cada sociedad. Por otra parte, la "cultura musical" está en estrecho contacto con las dimensiones simbólicas de lo político, y especialmente con el resto de las culturas artísticas -literarias, teatrales, visuales, etc.- (Guillamón, 2014 y 2018). De esta forma, la perspectiva que ofrece la historia cultural constituye un abordaje pertinente, ya que se ocupa de los diferentes modos en que los individuos o grupos usan, interpretan y se apropian de los motivos intelectuales y las formas culturales (Chartier, 1995). ¿Es factible, entonces, concebir las revistas de música como revistas culturales?

\section{Revistas de música, revistas culturales}

Las revistas culturales constituyen objetos-agentes activos que interpelan una época y al mismo tiempo son interpelados por ella. En otras palabras, se trata de "estructuras esenciales de sociabilidad" (Pita González, 2014; Delgado, 2014, p. 21). Estructuras lábiles pero que, conformadas por la voluntad asociativa de grupos específicos, delimitan espacios comunes de acción. De esta manera, retomando el enfoque de Maurice Agulhon (1994), las revistas serían producciones culturales registradas como resultado de relaciones sociales y redes de sociabilidad tanto formales como informales -más allá de las dificultades para rastrearlas en los corpus documentales. En sus comienzos, las publicaciones periódicas formaron parte de la nueva sociabilidad literaria e intelectual de comienzos del siglo XX, "junto con otras prácticas como los homenajes, presentaciones, despedidas, agasajos, banquetes, demostraciones, bienvenidas, que se materializaron en espacios" (Delgado, 2014, p. 21). Por ello, según Williams (1980), para comprender una formación cultural -una revista, por ejemplo- resulta imprescindible, en primer lugar, conocer la organización interna del grupo y -al mismo tiempo- sus relaciones sociales con otros grupos.

\footnotetext{
${ }^{2}$ Agradezco los comentarios de Patricia Artundo sobre una versión preliminar de este trabajo, así como las sugerencias de revisión hechas por los pares evaluadores.
} 
Como señala Hanno Ehrlicher, es difícil definir qué es una revista cultural. Por su falta de actualidad, de universalidad, su menor periodicidad, tirada y difusión -es decir, por estar dirigidas a un público restringido o parcial-, en comparación con los periódicos, "las revistas fueron durante mucho tiempo, sino un medio completamente olvidado, sí marginado" (2014, pp. 26-27). Podría decirse que, a partir del cuestionamiento crítico a la Modernidad, abierto en la década de 1960, y la consiguiente valoración de lo nuevo -por ejemplo, de la juventud como actor social y con ella, la aparición del concepto de contracultura-, las revistas fueron resignificadas como medios eficaces y alternativos en el contexto de sociedades altamente politizadas. Las investigaciones académicas comenzaron a enfocarse en dichos medios gráficos, primero para el estudio de lo literario y luego como insumo de análisis cultural-sociológico e histórico, en consonancia con el desarrollo de las teorías culturales. En este sentido, debe comprenderse el actual impulso memorialista y patrimonial por la digitalización de colecciones y corpus documentales cuya vida material se evalúa precaria.

En el caso de las revistas de música, Leandro Donozo (2012) ha señalado una serie de reflexiones muy interesantes. En primer lugar, que la historia de las revistas de música argentinas es todavía un proyecto pendiente, ya que aún estamos en la etapa de buscar dónde se han conservado ejemplares:

Las colecciones con las que el estudioso cuenta, son abrumadoramente incompletas, y el continuo hallazgo de sus publicaciones hasta ahora casi olvidadas y de las que se tiene escasa o nula referencia bibliográfica previa, nos da la pauta de que no hemos hecho más que empezar a explorar este mundo vasto, rico y diverso (Donozo, 2012, p. 19).

La Guía de revistas de música de la Argentina (1829-2007), elaborada por Donozo (2009), reúne 450 títulos en ese lapso de tiempo. Es decir, sin contar los hallazgos posteriores a la fecha indicada como límite. Por ejemplo, la Guía nombra la Revista de la Asociación Wagneriana y le atribuye un lapso cronológico que, hoy sabemos, es más amplio del allí registrado, aunque no contemos con la totalidad de los números editados.

En la presente indagación, adoptaremos un enfoque más vasto que el de concebir a las revistas de música como medios especializados de un campo artístico en particular, en este caso, el musical. Las revistas de música pueden ser también revistas culturales, ya sea que -siguiendo a Williams (2000, p. 91)- adoptemos una definición de cultura restringida (como 
sustantivo que describe obras y prácticas de la actividad intelectual y en especial artística) o abierta (como sustantivo que designa un proceso general de desarrollo intelectual, espiritual y estético desde el siglo XVIII, o, en sentido antropológico, como modo de vida determinado -códigos de percepción, valores, costumbres, etc.- de un pueblo, un período, un grupo o la humanidad en general). De esta forma, entender las revistas dedicadas a la música como redes de sociabilidad cultural e intelectual permite integrarlas a los sistemas sociales de los cuales formaron parte y comprenderlas en sus contextos. Sin soslayar la importancia del análisis estético, nuestras preguntas apuntan a indagar lo que los grupos humanos hacen con las obras musicales en particular. ${ }^{3}$ En tanto producto de patrones sensibles de significación, el hecho estético es también un acontecimiento intrínsecamente político e incluso ético y filosófico. En América Latina, "la relación entre arte y política aparece no solo como un síntoma, propio del puente histórico que se transita en los años 20, sino como una modalidad del proceso de autonomización de lo cultural" (Beigel, 2004, p. 445).

El eje que vertebra nuestro análisis es el de los tiempos editoriales o momentos vitales. ${ }^{4}$ En cada momento vital indagaremos someramente en el contexto cultural (el rol formativo que asumió la revista en relación con las prácticas musicales); la composición y devenir de su núcleo editorial (dirección, colaboradores permanentes y temporarios, etc.); la sintaxis de la publicación, su forma de organización y de intervención colectiva como espacio de enunciación, que en nuestro caso, contiene una voluntad programática; su contexto de edición, es decir, sus políticas específicas de crítica, edición, divulgación, traducción, promoción de ideas, figuras y sus vínculos con otras publicaciones; su contexto de producción (circulación, distribución, venta, organización de las secciones, periodicidad, lugares de impresión, tirada, formas de financiación (Delgado, 2014, p. 22), y su contexto de publicación (la puesta en página de los textos y las imagines, y del sentido que dicha puesta contiene). Este análisis permite "señalar en cuáles la práctica tiene un peso mayor que el 'soporte' y en cuáles los 'soportes' juegan un papel fundamental para redefinir viejas prácticas o generar nuevas" (Pita González, 2014, p. 236). Así, se suele pensar que los procesos de modernización cultural de comienzos de siglo XX tuvieron a las revistas como instrumento (Sarlo, 1992), pero también cabe señalar lo

\footnotetext{
${ }^{3}$ Esta perspectiva de análisis -que permite pensar nuestro objeto-, se apoya en la teoría de las mediaciones culturales (Hennion, 2003 y 2012; DeNora, 2002). Estos abordajes -orientados por el giro pragmático-, han puesto el foco en los modos en que la música estructura y habilita la acción social, tomando distancia de otros enfoques centrados en el arte como expresión del estatus, de dominación ideológica o como capital cultural.

${ }^{4}$ Un ejemplo de análisis en base a tiempos editoriales puede encontrarse en Artundo (2004).
} 
contrario, que las mismas revistas le dieron determinadas características a ese proceso, interviniendo en la opinión pública y en la cultura.

\section{Primera época (1913-1914): medio de difusión y “tribuna de arte y cultura"}

Durante la década de 1910 surgieron nuevas entidades creadas para superar la centralidad de las temporadas líricas en torno al Teatro Colón. Entre estas nuevas agrupaciones, podemos nombrar a la "Asociación italiana de conciertos", fundada por el músico Ferruccio Cattelani, y la "Sociedad argentina de música de cámara", creada en 1911 por los catalanes León Fontova y Juan Llonch. Al igual que en otros campos, la celebración del Centenario de la Independencia en 1910 fue un acontecimiento que marcó la búsqueda de un lenguaje -musical en este caso- que identificara a la nación (Pujol, 2013). Según Suarez Urtubey (2010), fue el punto de inflexión de una tendencia que intentaba fusionar el folclore del interior con la música europea, con una nueva que comenzaba a definirse y que recuperaba tradiciones musicales de los pueblos indígenas prehispánicos.

En este contexto de renovación, a finales del año 1912, un colectivo de inmigrantes catalanes (José Lleonart Nart, ${ }^{5}$ José María Pena, Ignacio París y Pablo Henrich) unidos a Ernesto de la Guardia, ${ }^{6}$ y al crítico musical Mariano Barrenechea, ${ }^{7}$ entre otras personalidades, concretaron una Asociación Wagneriana en Buenos Aires, según el modelo de su homónima en Barcelona, gestada en 1901. Esta reunión inicial no prosperó y la

\footnotetext{
${ }^{5}$ Josep Lleonart i Nart arribó a Buenos Aires en 1906. En Barcelona, fue maestro y fundador del Colegio Montessori, crítico teatral y musical. Fue un destacado dirigente de la colectividad catalana afín al separatismo: fundó el Casal català, el "Instituto de estudios catalanes", la peña "El soviet", entre otros espacios.

${ }^{6}$ Ernesto de la Guardia (1885-1958) fue crítico y musicógrafo español. En Argentina, donde se radicó a los 25 años, ejerció la crítica musical en los diarios La Prensa (1915-1922); La Razón y La Nación (1927-1929). Fue profesor de Historia de la música en el Conservatorio Nacional de música y arte escénico de Buenos Aires (cuyo impulso fundador provino de la Wagneriana) y profesor de arte lírico en el Instituto de arte del Teatro Colón, además de escribir y publicar varios libros sobre música.

${ }^{7}$ Graduado en Derecho y Filosofía, Mariano A. Barrenechea fue profesor de Estética en la Facultad de Filosofía y Letras de la Universidad de Buenos Aires, periodista, escritor, musicólogo y diplomático, introductor de las ideas del filósofo F. Nietzsche en Argentina. Ejerció la crítica literaria y musical en los diarios La Nación (1906-1914), El Diario (1914-1937) y revistas como Ideas y Nosotros. Publicó varios libros y una considerable cantidad de artículos sobre temas de literatura, estética e historia del pensamiento.
} 
iniciativa Wagneriana se disolvió. ${ }^{8}$ En junio de 1913 , los catalanes ${ }^{9}$ dieron un impulso decisivo para la reorganización de la Asociación, ocupando cargos relevantes dentro de la misma; Lleonart i Nart como presidente, y Pablo Henrich como secretario general. ${ }^{10}$ Esta reorganización ocurrió en el local social del "Instituto de estudios catalanes", institución que había sido creada por Lleonart i Nart con el objetivo de potenciar la vertiente cultural de las actividades catalanas.

El proyecto de la revista resurgió ${ }^{11}$ en el mes de diciembre de 1913 -al menos oficialmente. Por entonces, la presidencia de la Asociación estaba a cargo de Rafael Girondo, ${ }^{12}$ quien había sido elegido en el mes de noviembre mediante asamblea general. ${ }^{13}$ Ese mismo mes, Ernesto de la Guardia y Cirilo Grassi Díaz ${ }^{14}$ presentaron un presupuesto de imprenta, mientras Ramón Guitart $^{15}$ contactó con un corredor de avisos, a fin de publicar la revista cuando fueran reunidos los avisos necesarios. En enero de 1914, volvió a pedirse presupuesto a la misma imprenta, pero solicitando un papel más liviano y con la inclusión de grabados. ${ }^{16}$ Esta aproximación a su contexto de producción inicial nos muestra una revista que originalmente se pensó

${ }^{8}$ La composición social de la primera Wagneriana estuvo relacionada en parte con la "generación del '80": como presidente el músico Julián Aguirre, vicepresidente Carlos Tornquist; secretario Ernesto de la Guardia, bibliotecario Rafael Girondo; y entre los vocales: Luis Drago Mitre; Luis Silveyra; Jorge M. Rojas Acevedo, y Miguel Cané (h). El resto de los cargos fueron ocupados por el catalán Pablo Henrich, como secretario, Roberto Carman como tesorero; Santos Gómez, Baudilio Alió y el pianista Ernesto Drangosch, como vocales.

${ }^{9}$ Anteriormente, una parte importante de este grupo había iniciado su vida asociativa dentro de la comunidad organizada inmigrante, a partir de la concreción del Casal Catal (1908), como entidad escindida del pionero centro de sociabilidad Centre Català, que reconocía como primordial la nacionalidad española.

${ }^{10}$ Como socios asistentes a este acto de reorganización se encontraban también los catalanes José María Pena, José Lleonart Giménez (hijo de Lleonart i Nart), Pere Seras, Jerónimo Zanné, etc.

${ }^{11}$ Uno de los principios del Acta fundacional (1912) había previsto fundar una revista mensual Actas de la Asociación Wagneriana de Buenos Aires (en adelante AAWBA), Libro I, 1912, material inédito.

${ }^{12}$ Rafael Girondo (1888-1940), hermano del famoso poeta, Oliverio. Descendiente de una acaudalada familia, fue un gran coleccionista de arte, presidente del Directorio del Teatro Colón, miembro fundador de la Asociación Amigos del Arte, y académico de número de la Academia Nacional de Bellas Artes.

${ }^{13}$ Desde julio a noviembre de 1913 la presidencia provisoria quedó a cargo de Josep Lleonart i Nart. Según las actas, una vez que se fijaron los estatutos, se consiguió una sede física -un local estable-, se organizaron las primeras actividades, y se recibieron adhesiones, se procedió a elegir una comisión directiva definitiva.

${ }^{14}$ De origen uruguayo (1883-1970), Cirilo Grassi Díaz fue uno de los más afamados directivos del Teatro Colón, empresario cultural y funcionario artístico. Dirigió el Teatro San Martín entre los años 1962 y 1967.

${ }^{15}$ Nacido en Badalona -Barcelona- Guitart (1880-1921), fue músico y pedagogo. Arribó a Buenos Aires en 1910 donde fundó una escuela de canto y fue maestro de capilla de la Iglesia de Las Victorias. Enfermo, retornó a Barcelona en 1917, donde falleció al poco tiempo.

${ }^{16}$ AAWBA, Libro I, 5 de enero 1914. 
con una periodicidad mensual, cuya forma de financiación procedería en gran parte de los avisos publicitarios y que tendría -según el presupuesto solicitado a la imprenta Escoffier, Caracciolo y Cia- 12 páginas (8 en papel velino y 4 en papel ilustración, con tapa a color) a un costo de $\$ 0,25$ por ejemplar (300 ejemplares).

La Revista se editó inicialmente durante todo el año 1914, luego se interrumpió hasta su reaparición en 1917 bajo otro formato visual. En 1918 cambió nuevamente su formato y desde allí se continuó editando hasta 1926 con algunas interrupciones. Finalmente, a partir de 1927 y hasta 1929, pasó a ser una sección de "La revista de música”, publicada por la casa Ricordi, editora de música y establecida en Buenos Aires, en $1924{ }^{17}$ Delimitamos estos cuatro momentos vitales y analizaremos los tres primeros en particular, para reconocer -como expresamos anteriormente-, cuándo y cómo el soporte fue estructurado por el grupo (como "estructura esencial de sociabilidad") y cuándo, al adquirir peso, estructuró la práctica; así como la pregunta por la valoración del grupo hacia la revista y la construcción de significados sobre la misma.

La publicación fue asumida como una tarea colectiva por parte de la Comisión directiva de la Asociación. Fue así que la primera nota editorial, estaba dirigida "Al lector" y firmada por "La comisión”, y en las páginas interiores no se halla ningún recuadro o detalle que especifique los nombres propios del equipo editorial (rasgo que se mantuvo hasta su final en 1926), ni siquiera un índice de los cronistas y colaboradores. Esto último cambió en la tercera época (desde 1918), donde la portada fue justamente un sumario del contenido. En este sentido, las portadas y la página inicial de los cinco números de la primera época, tienen como protagonista al propio Wagner, o en un caso, a uno de sus dramas musicales. Sin embargo, consultando las actas institucionales de la Asociación podemos conocer algunos nombres que estuvieron vinculados a esta primera época. A comienzos de febrero de 1914, se formó una comisión encargada de la confección de la revista, integrada por de la Guardia (quien luego fue designado como su director, bajo remuneración asignada) Rafael Girondo, y Cirilo Grassi Díaz (quien se ofreció a administrarla ad honorem). Pero quienes escribieron en la revista, -como redactores permanentes en todos los números-, fueron

\footnotetext{
${ }^{17}$ El corpus de revistas que hemos hallado es fragmentario. Contamos con números de 1914, (año I, N 1 a 5), de 1917 (renombrado como año I, del Nº 2 al 9), 1918 y 1919 ( $N^{\circ} 10$ a 30), todos ellos disponibles en la Hemeroteca de la Biblioteca Nacional. Posterior a esta fecha hallamos dos números, uno de 1920 ( $\left.\mathrm{N}^{\circ} 34\right)$, y otro de 1926 (ํㅛ 83) y varios números de La revista de música en la que la Wagneriana publicó su Boletín entre 1927 y 1929, en el archivo de la editorial Gourmet Musical.
} 
Lleonart i Nart, Jerónimo Zanné, ${ }^{18}$ y de la Guardia. ${ }^{19}$ Los dos primeros introdujeron de manera asidua como colaboradores temporarios, a críticos e intelectuales catalanes residentes en Barcelona. ${ }^{20}$

Luego de la breve editorial del primer número, el artículo inicial fue un repaso de la historia de la Asociación extraído entre comillas de un discurso pronunciado por Lleonart i Nart, que ponía de relieve el contexto internacional de asociacionismo wagneriano al que se había unido la nueva entidad porteña. En esta primera época (1914), la presencia del grupo catalán dejó su impronta (más allá de la pluma ocasional de Ernesto de la Guardia) en la publicación, difundió las prácticas llevadas a cabo en la Asociación, -sobre todo las conferencias pronunciadas en diversas veladas-, y gran parte de las temáticas que ejercían una función dominante en ella.

El interés primordial de la dirección de la Revista -el de constituirse en órgano de difusión de la entidad y al mismo tiempo registrar la vida musical porteña-, quedó explícito en el primer número:

Esta publicación será el medio más eficaz para la propaganda de nuestros ideales, que pueden resumirse en el siguiente lema: Arte y cultura. Su principal objeto es el de servir gratuitamente a sus asociados, y a un módico precio al público filarmónico en general, todos los trabajos críticos y literarios que se den a conocer en la Asociación Wagneriana bonaerense [...] Además, se podrá encontrar el estado y movimiento artístico mensual de la Asociación [...] Otras dos secciones están dedicadas al comentario crítico de los importantes acontecimientos musicales que se celebren en nuestra capital, y a la información de actualidades liricas extranjeras, reproducción de crónicas, noticias artísticas, etc. ${ }^{21}$

\footnotetext{
${ }^{18}$ Nacido en Barcelona, (1873-1934) Zanné fue uno de los referentes del movimiento modernista catalán tanto en lo literario como en lo musical. Fue miembro fundador, luego vicepresidente y bibliotecario de la Asociación Wagneriana de Barcelona, fundada en 1901 y tradujo dramas wagnerianos al catalán, además de otros poetas italianos y franceses. Emigró a Buenos Aires en 1913, donde publicó algunos poemas y ejerció el periodismo como redactor de "El correo musical sudamericano", la revista de la Wagneriana, La revista de música, Ressorgiment, etc.

${ }^{19}$ El vicepresidente de la Wagneriana escribió siete artículos firmados, Jerónimo Zanné cuatro, y Ernesto de la Guardia tres artículos, más un suplemento sobre "El buque fantasma" (drama musical de Wagner también llamado "El holandés errante").

${ }^{20}$ El crítico musical Miquel Domenéch i Español y el periodista Eugenio Xammar (famoso luego por sus críticas crónicas sobre el ascenso del nazismo en Alemania). Otros colaboradores temporarios fueron los músicos y críticos Tulio Quercia, Ángel Menchaca y Roque Otamendi.

${ }^{21}$ Revista de la Asociación Wagneriana de Buenos Aires (en adelante RAWBA), Año 1, Número 1, febrero de 1914, p. 1.
} 
Más allá de estos objetivos programáticos, existió una inestabilidad en la continuidad de las secciones. Sólo "Crónicas europeas" (sin firma de autoría) y "Juicios críticos" se perpetuaron durante dos números. ${ }^{22}$ Para ésta última sección, escribieron (una vez cada uno) Zanné y de la Guardia. El primero, mostró ya en el número inicial (segundo artículo después de Lleonart i Nart) los intereses temáticos que preocupaban a los catalanes wagnerianos, respecto a la lengua, el problema de la traducción y el aspecto dramático de la obra Wagneriana. En relación a la primera, se colocó como ejemplo a imitar del "maestro", su rescate del antiguo idioma alemán, "estupendo trabajo filológico". ${ }^{23}$ Esta sección fue acompañada de dos grabados (retrato de Wagner en 1842, y otra ilustración sobre El holandés errante, sin indicación de la fuente donde fueron sustraídas las imágenes).

La revista se pensó con una periodicidad mensual y una tirada de 400 ejemplares. Según indica el primer número, en 1914 el número de socios de la Wagneriana ascendía a $156 .{ }^{24}$ Por ello, se pensaba en un público lector más amplio que el constituido por los socios, aunque de todos modos, no dejaba de ser una tirada reducida, para un público reducido -interesado en la especialidad temática de la publicación. La revista comenzó a editarse cuando fue exitosa la convocatoria de avisos publicitarios, de modo que el financiamiento para su edición se sustentó sobre todo en los avisos que estaban relacionados con el mundo del arte: academias de canto, de música, dibujo y pintura, conservatorios y colegios, casas de venta de instrumentos musicales, y en menor medida (desde el tercer número, cuando decayeron los avisos), de otros rubros comerciales y profesionales: salón de belleza, neumáticos, sastrería, agencia de publicidad, dentista, y fábrica de muebles de bronce. Sólo las casas de venta de instrumentos invirtieron más en publicitar en la revista, y a página completa incluyeron una ilustración.

Para el N 3 (marzo), la obtención de financiamiento a partir de los avisos se había hecho difícil. En razón de ello, la comisión decidió abaratar la publicación, excluyendo el añadido de grabados, decisión que para el $\mathrm{N}^{\circ}$ 4 (abril), se dejó de lado en el caso de la tapa para Parsifal y la publicidad de la primera página. ${ }^{25}$ Para mayo, las dificultades para reunir dinero para la revista aumentaron, y la comisión resolvió llamar a asamblea

\footnotetext{
22 "Citas de Autores", “Los grandes maestros", "Notas de Arte” y otras notas anónimas sólo aparecieron una sola vez.

${ }^{23}$ RAWBA, Año 1, número 1, febrero de 1914, p. 7. Zanné y otros musicólogos y aficionados catalanes habían emprendido en Barcelona la traducción de Wagner al catalán.

${ }^{24}$ RAWBA, Año 1, número 1, febrero de 1914, p. 6.

${ }^{25}$ AAWBA, Libro I, 23 de marzo 1914.
} 
extraordinaria a todos los asociados para dar cuenta de las dificultades y pedirles a los socios que proporcionasen recursos suficientes para continuar su publicación. Según Girondo, en junio, la publicación de la revista ocasionaba un déficit mensual aproximado de 150 pesos. ${ }^{26}$ Lleonart i Nart propuso conformar "una comisión especial compuesta de 3 miembros para que trate por todos los medios a su alcance, de prestigiar dicha publicación consiguiendo avisos, suscripciones y propagarla todo lo más posible". ${ }^{27}$ La consiguiente renuncia de Cirilo Grassi Díaz como administrador, y el fracaso de la comisión nombrada, llevaron a la suspensión de la revista a partir de julio. En agosto, se imprimió una nota dedicada a socios y suscriptores, donde se anunciaba que debido a las circunstancias (comienzo de la Primera Guerra), no podría publicarse la revista.

La dirección indicaba en un recuadro de la publicación (en la página dedicada a los avisos publicitarios) que podía adquirirse en ocho puntos de venta distribuidos en la Capital. De acuerdo al artículo 12 del estatuto de la Asociación, la revista era gratuita para los socios, y luego tenía un precio de suscripción para el interior (anual o semestral), otro para el exterior, así como para el número suelto y para el atrasado. En este sentido, la publicación debió contar con una amplia difusión y repercusión incluso en el extranjero, ya que en 1915 recibió una distinción de la Exposición Universal de San Francisco (California, Estados Unidos), que debido a la interrupción de las comunicaciones, fue recibida una vez finalizada la guerra, en 1919.

En cuanto a la política de traducciones, que había sido anunciada como un eje de la revista, sólo pudo concretarse la de una conferencia del director artístico de la Wagneriana de Barcelona, M. Domenech i Español, traducida por el catalán José María Pena. ${ }^{28}$ Si bien se había encargado a Zanné la traducción al castellano del poema del drama musical "Parsifal" (con motivo de su estreno en el Teatro Colón), el escritor catalán no pudo hacerlo por falta de tiempo. ${ }^{29}$ Dicha labor de "importación cultural" -aunque escasaestuvo a cargo del grupo de catalanes, y puso por escrito una actividad oral (conferencia) ocurrida en la entidad homónima barcelonesa.

\footnotetext{
${ }^{26}$ AAWBA, Libro I, 11 de mayo y 3 de junio de 1914.

${ }^{27}$ AAWBA, Libro I, 3 de junio de 1914.

${ }^{28}$ Fusión del más puro y sereno clasicismo y del mas fogoso romanticismo en el arte de Wagner, RAWBA, Año 1, número 5, junio de 1914, pp. 82-88.

${ }^{29}$ AAWBA, Libro I, 18 de abril de 1914.
} 
En este contexto editorial, se desarrollaron íntegramente en el seno de la publicación -o gracias a ella- al menos dos polémicas, que remitían al ámbito local y el europeo. En el primer caso, el número 2 abrió con una carta enviada por Carlos Octavio Bunge ${ }^{30}$ (quien había estado en la primera fundación de la Asociación, en 1912). Dicha carta, denominada "La afición a la música en Buenos Aires. Estímulo necesario"31 despliega entre otros tópicos, un diagnóstico sobre las tradiciones de música popular en Buenos Aires, que según él respondía a elementos hispánicos y criollos y no indígenas, confrontando de esa forma con la tendencia indigenista que representó Ricardo Rojas -quien sería declarado meses después, "primer socio honorario de la Wagneriana" (Irurzun, 2017a y 2019)-, y la falta un público de conciertos numeroso y asiduo. Proponía entonces que la Asociación gestionase una solicitud de subvención a la municipalidad para apoyar la concreción de una serie de conciertos sinfónicos a módico precio. En el número siguiente, puede encontrarse la respuesta de Llenoart i Nart quien argumentaba que, si bien toda obra wagneriana era obra de cultura, resultaba difícil conformar a un público diverso "por razones étnicas de gustos y aficiones tan distintos". En su opinión, la posibilidad de organizar "estas fiestas espirituales" dependía más de la existencia de músicos capaces de conformar orquestas de concierto, que de la formación de un público. ${ }^{32}$

La otra polémica, que tenía asidero en el contexto internacional, tuvo que ver con la importancia del análisis de Parsifal $^{33}$ (que ya estaba en el número 1, en la sección "Crónicas europeas") y que quedó plasmada, en primera instancia, en el número 3. En "Aclaraciones breves a un artículo de Max Nordau", Zanné se manifestó en contra de la interpretación (considerada errónea) de Nordau, ${ }^{34}$ que no veía en Parsifal una obra de arte, sino de glorificación del cristianismo.

\footnotetext{
${ }^{30}$ Carlos Octavio Bunge (1875-1918). Escritor, sociólogo y jurisconsulto, se convirtió en una referencia del pensamiento positivista durante la última parte del siglo XIX y comienzos del XX.

${ }^{31}$ RAWBA, Año 1, N 2, febrero 1914, pp. 17-19.

${ }^{32}$ RAWBA, Año 1, N 3, Marzo 1914, pp. 29-32. Sobre los conciertos y actividades ofrecidas por la Asociación Wagneriana pueden verse los trabajos de Dillon (2007), Mansilla (2004), e (Irurzun, 2015a, 2015b y 2017b), entre otros.

${ }^{33}$ Parsifal (drama wagneriano que transcurre parcialmente en el castillo de Monsalvat, norte de España) permitía vincular el wagnerianismo con la voluntad modernista de Cataluña.

${ }^{34}$ Max Nordau (1849-1923) fue un crítico, escritor, publicista y médico europeo. De cuño positivista, era crítico de las corrientes modernistas y decadentistas, por ende del wagnerianismo, cuyo encono era mayor porque formaba parte del movimiento sionista. El articulo al que hace referencia Zanné fue El canto del cisne.
} 


\section{Segunda época (1917): tiempos de refundación}

El elemento quizás más llamativo de la segunda época de la revista es la negación que se realizó de la primera, ya que no sólo se diferenció completamente desde el punto de vista estético (diagramación, tipografía, tipo de papel, portada, organización de los artículos, secciones, etc.), sino que fue completamente borrada como su antecesora en la construcción de la memoria colectiva de la entidad. Esto lo indica la decisión de nombrar al año 1917 como "Año 1". Lamentablemente no contamos con el número 1 de la segunda época, (ya que el tomo 2 encuadernado en la Hemeroteca de la Biblioteca Nacional, inicia con el número 2), que permitiría conocer el contenido del editorial que dio comienzo a esta segunda época. Al igual que en la primera, la publicación no indicaba el equipo editorial que la producía.

Es probable que la re-edición de la revista y el deliberado "olvido" de la primera época tuvieran que ver con un cambio en la dirección de la entidad. Es decir, esta segunda época -al igual que la primera- se vio fuertemente afectada por la dinámica de la institución. A partir de febrero de 1917 ocurrió una reorganización de la comisión directiva de la entidad (bajo la presidencia de Carlos López Buchardo, iniciada en 1916) y se nombraron sub-comisiones, entre ellas, una dedicada a la organización de la revista. Días antes, Lleonart i Nart había pedido que se elevara una nota a la Comisión argentina encargada de la Exposición de San Francisco para que fuera remitido el premio que la revista había obtenido en 1915 (AAWBA, 29/01/1917). En la memoria de 1919, se informa finalmente sobre la obtención de la distinción. ${ }^{35}$

La Sub-comisión encargada de la revista, consiguió rápidamente un presupuesto económico en la imprenta Escoffier, Caracciolo y Cia., los avisos de ocho casas de venta de instrumentos musicales y del conservatorio Scaramuzza. Posteriormente se decidió que la dirección recayera en López Buchardo, y Ernesto de la Guardia (director artístico de la entidad), la redacción quedó a cargo del músico Athos Palma, y la administración a cargo del vicepresidente Cirilo Grassi Díaz (AAWBA, 5/02/1917).

\footnotetext{
35 “El jurado de la Exposición internacional de San Francisco, celebrada en 1915, otorgó medalla de honor a esta Asociación y otra a la revista de la misma, a más de los correspondientes diplomas. Por motivos de la guerra, las mencionadas medallas y los diplomas no llegaron hasta el presente año a esta Asociación, que agradece, en lo que valen, tan honrosas distinciones" (Memoria y Balance de la Asociación Wagneriana de Buenos Aires, en adelante, MBAWBA, 1919, p. 22).
} 
Observamos además la ausencia de colaboraciones por parte de Zanné y Lleonart Nart, y la aparición de una sección "Actualidades artísticas", que a lo largo de esta segunda época fue incrementando su importancia desde el número 2 (con letra más pequeña y en un rincón de las páginas 2 y 3) al número 4, en primera plana y con el despliegue de tres páginas de un total de ocho que tenía la revista. Estas "Actualidades" -escritas por Athos Palma- registraban la actividad del Colón, de la Sociedad argentina de música de cámara, del Conservatorio de Buenos Aires, de la Sociedad nacional de música, de otras agrupaciones musicales recientes, de las visitas de reconocidas personalidades musicales y de la propia Wagneriana. El resto de las páginas reproducían conferencias leídas en la Asociación (práctica continuada desde la primera época) -entre ellas, la sección más importante que ocupó las contratapas: la serie de conferencias pronunciadas por Ernesto de la Guardia sobre las sonatas de Beethoven- algunas notas de opinión firmadas, otras anónimas, y una sección técnica (del número 6 al 9) sobre "Psicología de la tonalidad" que sintetizaba principios musicales de Alberto Mazzucato. Las traducciones prácticamente se perdieron, tanto en la intención como en la concreción, sólo hallamos una nota atribuida al músico francés Gustave Fauré, pero no se indica su procedencia ni quién fue su traductor.

En esta época también se editó la revista con una periodicidad mensual, y la fuente de financiamiento pareció más organizada y estable, sostenida por la continuidad de los mismos avisos publicitarios. Éstos últimos eran de casas de instrumentos musicales, conservatorios, academias, artistas, y se excluyeron aquellos que no referían a lo musical o artístico.

Salvo el número 3, que tenía dieciséis páginas, el resto se desplegaba en ocho. La puesta de los textos se diagramó en una página amplia, de grosor muy fino, con tres columnas, donde (a diferencia de la primera época) se intercalaban los avisos publicitarios, sistemáticamente en los mismos lugares. Es decir, se eligió un formato tipo periódico, carente de imágenes ilustrativas (sólo las publicidades cuentan con algún dibujo). Estas decisiones dieron como resultado una publicación mucho más económica que la de la primera época, es por ello que suponemos que la tirada fue mayor a 400 ejemplares -la cantidad de 1914-, aunque no podemos saberlo con exactitud. ${ }^{36}$

\footnotetext{
${ }^{36}$ En la portada/primera página de la revista se indicaba el precio (más módico que la primera época, ya que contaba con menos páginas y más delgadas, sin tapa y contratapa) del número suelto y la suscripción anual. Como no se indican los puntos de venta, resulta difícil saber si amplió su posible circuito de difusión o permaneció igual a la primera época.
} 
La numeración se iniciaba cada mes desde 1 a 8, en correspondencia con una intención de informar las novedades musicales más importantes, y en ese sentido -más allá de los artículos de opinión y conferencias transcriptas- imprimía un modo de leer más intensivo para su lector contemporáneo.

Cabe señalar el poco perceptible - pero significativo- cambio de portada que ocurrió desde el número 2 al 3 (abril a mayo), que excluyó en este último al pequeño retrato de Wagner, cambió el color de la letra de negro a gris, agrandó "Buenos Aires" y quitó el recuadro ornamentado que rodeaba al nombre de la Revista. El diseño del número 3 se mantuvo hasta el último de esta época, el 9 (diciembre de 1917). Dicho cambio pudo haber estado relacionado con la propuesta hecha por E. de la Guardia en el mes de junio, de cambiar el nombre de la Asociación Wagneriana, en vista de los acontecimientos internacionales. Pero, dicha moción fue rechazada por unanimidad, y pudo haber sido causa de la posterior renuncia de la Guardia como director artístico de la entidad. ${ }^{37}$

\section{Tercera época (1918-1926): la estabilidad}

En la Memoria anual de 1917, la comisión directiva de la Wagneriana señaló un cambio de formato, además de la apertura de la publicación y su enriquecimiento con importantes colaboraciones de interés general. En enero de 1918, las actas registraron la resolución de nombrar un jefe de redacción que fuera externo a la comisión directiva, y con una remuneración que se fijaría oportunamente. Para esta función, se acordó nombrar a Jerónimo Zanné, quien aceptó el cargo. Su figura adquirió protagonismo desde ese año, ya que además fue designado para ofrecer en la Asociación, un ciclo de conferencias sobre temas wagnerianos (AAWBA, 1918, p. 84).

En el hecho que los mismos autores llaman la "re-organización de la Revista", puede observarse también la inquietud por establecer vínculos con otras publicaciones literarias, culturales o intelectuales, es decir, más allá de las específicamente musicales. En este sentido, la sugerencia de tomar como modelo la diagramación y estética de le revista La nota, ${ }^{38}$ fue una clara señal de ello. En 1918, la comisión decidió suscribirse a la revista Nosotros, posiblemente como forma de vincularse con el campo literario

\footnotetext{
${ }^{37}$ AAWBA, Libro 2, pp. 22-24.

38 "Tercer informe de la Subcomisión Revista: esta SC aconseja la edición de nuestra revista en el formato que actualmente usa "La Nota" con ocho páginas de texto y cuatro de tapa. Se aprueba" (AAWBA, 1918, p. 84).
} 
e intelectual porteño y como estrategia de visibilización. Ese mismo año, Zanné publicó un artículo en ella. Anteriormente, en 1915, la comisión directiva había recomendado la suscripción con la revista Correo Musical Sudamericano, donde Zanné se desempeñaba como Jefe de redacción (AAWBA, 26/04/1915).

Hacia fines de la década de 1910, la Wagneriana contaba con una comisión directiva plural y una masa societaria muy diversa, pero comenzaba tibiamente a formar parte del proyecto nacionalizador. Como consecuencia de esa posición -que cada vez se afirmó más- fue blanco de críticas y aliado al mismo tiempo -según el tópico que estaba en discusión- de las vanguardias estéticas que tímidamente empezaron a asomarse a la vida porteña en esos años y se afianzaron sobre todo a partir de los años veinte. ${ }^{39} \mathrm{En}$ este sentido, se observa un cambio profundo entre la Wagneriana que actuó en la década del diez y la que se orientó de forma comprometida, durante los años veinte del pasado siglo, con los objetivos de la dirigencia política radical (Irurzun, 2014 y 2015b).

Luego de un balance de los logros alcanzados, el editorial de re-inauguración de la revista escrito por Zanné en 1918, señalaba algunas pretensiones performativas de convertir a la revista en eje del accionar de la Wagneriana, pero afianzando la intención de esta última de convertirse en una entidad ecléctica que traspasara lo musical.

Además de los tradicionales artículos de opinión de reconocidos críticos (Joaquim Pena, Miguel Mastrogianni, el propio Zanné, etc.), la publicación reseñaba las actividades más importantes llevadas a cabo por la Asociación y por las entidades cercanas a ella. Por ejemplo, el Orfeó Catalá del Casal Catalá de Buenos Aires ocupaba una sección en la revista, así como la de la Sociedad argentina de cúsica de cámara (fundada por los hermanos Fontova y Joan Llonch) y la recientemente creada, Sociedad nacional de música. Pero un elemento que la diferenciaba de las épocas anteriores, era la voluntad de instalar debates y polémicas a través de notas de opinión sobre la actualidad musical de Buenos Aires (sin firma, pero que puede suponerse, habían sido discutidas por la comisión directiva y redactadas por el jefe de redacción) y la inclusión de encuestas o respuestas a

\footnotetext{
${ }^{39}$ Dos personajes protagonistas de la fundación y dirección de la revista Martín Fierro, fueron socios más o menos activos de la Wagneriana en la década de 1910. Nos referimos en primer lugar, a Evar Méndez, quien cuatro años antes de fundar la famosa publicación, en 1915, escribió en la "Gaceta de Buenos Aires", participó de los encuentros wagnerianos y fue socio de la Asociación (AAWBA, 19/04/1915). Asimismo, Gastón Talamón -“el defensor más consecuente de la música nacionalista argentina de entonces" (Corrado, 2010, p. 27)- no sólo fue miembro fundador de Martin Fierro sino asiduo colaborador de la Wagneriana a partir de 1918.
} 
encuestas. En el caso de la primera, un ejemplo muy claro fue la posición tomada en 1919 (contraria y de denuncia) ante la prohibición del silbido que habían dispuesto a los teatros las autoridades municipales de la Capital, o los balances críticos sobre las temporadas líricas del Colón y sobre el mismo teatro (Irurzun, 2018). En el caso de la segunda novedad, la más resonante fue la encuesta hecha por la Asociación a reconocidas personalidades nacionales e internacionales del mundo de la cultura, sobre la continuidad de la prohibición de la obra del compositor alemán en los teatros líricos del mundo, aún en 1919 cuando ya había concluido la guerra. Su repercusión fue notable, la cantidad de respuestas recibidas fue publicada por entregas sucesivas desde el número 26 (julio de 1919) hasta -al menos el último que encontramos- el número 34 (marzo de 1920). Un análisis de ella excede los propósitos de este trabajo. Cabe señalar que este activo posicionamiento de la revista formó parte de una "campaña pro-Wagner" emprendida por la Asociación (MBAWBA, 1919, pp. 12-14) cuyo objetivo era la reanudación de las funciones wagnerianas. Concluida la guerra, se responsabilizaba de las operaciones de censura a las casas editoriales de música del extranjero y a "los críticos reproductores de tópicos vulgares" (MBAWBA, 1919, p. 13). Finalmente, en 1920, los wagnerianos festejaron la reincorporación de la obra en los teatros líricos. De hecho, ese año se llevaría a cabo la primera transmisión radiofónica de la mano de los “Locos de la Azotea", entre los cuales se encontraba un vocal de la AWBA, Enrique T. Susini, quien, posiblemente, tuvo algo que ver en la elección de Parsifal (en el Coliseo) para la emisión inaugural.

La periodicidad de la publicación -hasta donde sabemos- fue mensual o bimensual, y la fuente de financiamiento se sostuvo por la continuidad de los mismos avisos publicitarios conseguidos en 1917 (con el añadido de academias musicales nuevas, por ejemplo, o productos externos al interés musical), y cuando no se llegó a cubrir con esto, se recurrió a la tesorería de la Asociación. Tuvo inicialmente 8 páginas de texto (algunas veces se extendió a 12) y 4 de tapa, sin ilustraciones (salvo las publicidades). A diferencia de la época anterior, éstas no se intercalaron con el texto, sino que se colocaron antes de la primera y después de la última página, continuando con la forma adoptada en la primera época. El grosor del papel era mediano, y la numeración se iniciaba desde el 1 en cada número, intentando conectar siempre al lector con las actualidades musicales, pero manteniendo también la posibilidad de un ritmo de lectura más extensivo en el tiempo, a través de las notas de opinión y sobre técnica musical.

La estética y los contenidos diagramados a doble columna por página, era similar a otras revistas de la época, como La nota. Se incluía una portada 
que indicaba el sumario o índice de los artículos. Este formato se mantuvo hasta su final, en 1926.

Al igual que en otras épocas, resulta difícil saber si amplió su circuito de difusión o permaneció en lugares semejantes. En 1918 la tirada fue de 600 ejemplares, pero es previsible que se haya incrementado, debido a que en 1920 la Asociación contaba ya con más de 1700 socios (MBAWBA, 1920). Si bien no hallamos números posteriores a 1920, por la Memoria institucional del año 1922 sabemos que la revista cambió su periodicidad a bimensual (MBAWBA, 1922).

\section{Reflexiones finales}

El análisis que hemos desarrollado sobre la revista de la Asociación Wagneriana de Buenos Aires ha considerado la publicación como un proceso con su propia historia y momentos vitales, y ha intentado subrayar en ese sentido, el carácter dinámico de la revista como soporte y estructura de sociabilidad. Si bien hace falta profundizar en varios aspectos, además de estudiar su último período editorial (como Boletín en La revista de música) es posible ensayar algunas reflexiones provisionales.

En primer lugar, podemos concluir que la revista jugó un rol destacado en la modernización de las prácticas artísticas, en la conformación del campo musical y cultural, en la formación del canon y la educación musical, entre otros aspectos. Por un lado como vocera de una institución, por otro -en tanto reunió en su seno ideas y prácticas de grupos heterogéneos, como los catalanes- como protagonista e impulsora de los debates culturales.

Como órgano de expresión y difusión de la Asociación Wagneriana porteña, el soporte material fue estructurado tanto por las prácticas sociales acaecidas en la institución (especialmente la acción de su comisión directiva), pero también por los espacios de la sociabilidad informal (el café, los hogares particulares, los salones de reunión, las comunicaciones personales, redes intelectuales y viajes) los vínculos con otras revistas e instituciones del campo intelectual, artístico y cultural, las polémicas y batallas de la época. Los cambios en la comisión directiva incidieron directamente en la dirección de la revista, y en ese sentido las distintas épocas o momentos vitales, permitieron mostrar "hasta qué grado el cambio necesita adaptar el discurso visual y textual de la misma, al cambiar la discursividad de imágenes y palabras" (Pita González, 2014, p. 238). En este sentido, la ruptura de Ernesto de la Guardia como director artístico 
de la entidad y de la revista, y su alejamiento en 1917, abrió la puerta para que al año siguiente se nombrara a Jerónimo Zanné como jefe de redacción de la misma. Esto llevó a reconsiderar, en la tercera época, la primera experiencia de la revista que había sido deliberadamente olvidada (aunque la numeración de los años continuó marcando el inicio en 1917).

Si bien la publicación intentó dar una continuidad a sus objetivos iniciales (ser vocera al mismo tiempo de la Asociación y de los acontecimientos musicales de la ciudad), éstos no siempre se vieron reflejados con igualdad en cada época. En la primera, se prefirió el eco de lo que pasaba en la Capital, la segunda época fue más equilibrada, y la tercera tuvo años volcados más hacia uno u otro objetivo, según lo requerían las circunstancias (por ejemplo, en 1919 y 1920, la exclusión del repertorio wagneriano en los teatros del mundo).

Pero la revista también estructuró la práctica y adquirió personalidad propia en tanto se definió y actuó como espacio de interpelación de la actualidad musical. El olvido de la primera época significó un desplazamiento de lo que ésta había significado (si bien había recibido un premio internacional), de sus principales colaboradores, debates e incluso del formato visual. El lugar dado posteriormente (tercera época) a opiniones que no siempre estaban de acuerdo con la línea editorial, mostró cierta apertura y pluralidad.

En síntesis, como ha indicado oportunamente Donozo (2012), el estudio de las revistas musicales -a partir de la explosión editorial de las publicaciones culturales- es una tarea por hacer. Sus múltiples posibilidades de indagación las convierten en recursos valiosos para la historia sociocultural de las prácticas y las culturas musicales. 


\section{Bibliografía}

》 Agulhon, M. (1994). Historia vagabunda. Etnología y política en la Francia contemporánea. México: Instituto Mora.

»Artundo, P. (2004). La Campana de Palo (1926-1927): una acción en tres tiempos. Revista Iberoamericana, 52(208-209), 773-793.

»Artundo, P. (2010). Reflexiones en torno a un nuevo objeto de estudio: las revistas". En IX Congreso Argentino de Hispanistas: el hispanismo ante el Bicentenario, Asociación Argentina de Hispanistas, Instituto de Investigaciones en Humanidades y Ciencias Sociales (UNLP/CONICET), Universidad Nacional de La Plata, La Plata.

» Beigel, F. (2004). El editorialismo programático. En H. Biagini, y A. Roig (Dir.). El pensamiento alternativo en la Argentina del siglo XX: identidad, utopía, integración (1900-1930) (pp. 445-453). Buenos Aires: Editorial Biblos.

»Chartier, R. (1995). El mundo como representación. Estudios sobre historia cultural. Barcelona: Gedisa.

»Corrado, O. (2010). Música y Modernidad en Buenos Aires 1920-1940. Buenos Aires: Gourmet Musical Ediciones.

»Croce, M. (2006). Las revistas literarias argentinas o una historia colectiva de la literatura local. En H. Lafleur, S. Provenzano y F. Alonso. Las revistas literarias argentinas: 1893-1967 (pp. 9-30). Buenos Aires: Ediciones El 8vo. Loco.

»Delgado, V. (2014). Algunas cuestiones críticas y metodológicas en relación con el estudio de revistas. En V. Delgado, A. Mailhe y G. Rogers (Coord.), Tramas impresas. Publicaciones periódicas argentinas (XIX-XX) (pp. 11-25). La Plata: UNLP.

» DeNora, T. (2002). Music in Everyday Life. Cambridge: Cambridge University Press.

»Dillon, C. (2007). Nuestras Instituciones Musicales II. Asociación Wagneriana de Buenos Aires. Historia y cronología. Buenos Aires: Dunken.

»Donozo, L. (2009). Guía de revistas de música de la Argentina (1829-2007). Buenos Aires: Gourmet Musical Ediciones.

»Donozo, L. (2012). Once conclusiones provisorias sobre las revistas de música. En S. Mansilla (Dir.). Dar la nota. El rol de la prensa en la historia musical argentina (pp.13-20). Buenos Aires: Gourmet Musical Ediciones.

》Ehrlicher, H. (2014). El estudio de revistas culturales en la era de las humanidades digitales. Reflexiones metodológicas para un debate. En V. Delgado, A. Mailhe y G. Rogers (Coord.). Tramas impresas. Publicaciones periódicas argentinas (XIX-XX) (pp. 26-45). La Plata: UNLP.

»Eujanián, A. (1999). Historia de revistas argentinas. 1900-1950. La conquista 
del público. Buenos Aires: AAER.

» Girbal-Blacha, N., y Quattrochi-Wilson, D. (1999). Cuando opinar es actuar. Revistas argentinas del siglo XX. Buenos Aires: Academia Nacional de la Historia.

» Guillamón, G. (2014). Reflexiones sobre música y política: lo visible y lo invisible de la cultura musical en las fuentes de principios de siglo XIX. Revista Electrónica de Fuentes y Archivos, 5(5), 129-141.

» Guillamón, G. (2018). Música, política y gusto. Una historia de la cultura musical en Buenos Aires, 1817-1838. Buenos Aires: Prohistoria.

» Heffes, A. (2012). La identidad revisitada. Revista Identidades, 3(2), 85-97.

»Hennion, A. (2003). Music and Mediation. Toward a New Sociology of Music. En M. Clayton, T. Herbert y R. Middleton (Eds.). The Cultural Study of Music. A Critical Introduction (pp. 80-91). New York y Londres: Routledge.

"Hennion, A. (2012). Melómanos: el gusto como performance. En C. Benzecry. Hacia una nueva sociología cultural. Mapas, dramas, actos, y prácticas (pp. 213-246). Bernal: UNQ.

» Irurzun, J. (2014). La Asociación Wagneriana de Buenos Aires a inicios del siglo XX: ¿un nacionalismo cultural de derecha? En E. Bohoslavsky, y O. Echeverría (Eds.). Las derechas en el Cono Sur, siglo XX. Actas del Quinto Taller de Discusión (pp. 31-50). Los Polvorines: UNGS.

» Irurzun, J. (2015a). El activismo cultural de los catalanes wagnerianos en Buenos Aires (Argentina, primeras décadas del siglo XX). Forma. Revista d'Humanitats, 11, 61-74.

»Irurzun, J. (2015b). El activismo cultural de los catalanes en Buenos Aires y el devenir de una institución musical (Argentina, primeras décadas del siglo XX). Revista Latino-Americana de Historia, 4(13), 8-23.

» Irurzun, J. (2017a). La unidad de la belleza. Parsifal y la estética Wagneriana en la obra de Ricardo Rojas. Hispamérica. Revista de literatura, 137, 41-48.

» Irurzun, J. (2017b). Redes de sociabilidad artística y cultural. Un estudio a partir del activismo wagneriano de los catalanes en Buenos Aires (Argentina, inicios de siglo XX). En A. Reguera (Dir.). Los vínculos que forman redes. Las dimensiones relacionales de lo social y sus articulaciones a escalas diferenciadas (pp. 222-248). Buenos Aires: Teseo.

" Irurzun, J. (2018). Bayreuth en Buenos Aires: los wagnerianos y el Teatro de Ópera (Argentina, 1896-1914). Revista Estudios del ISHIR, 8(22), 1-17.

» Irurzun, J. (2019). Ricardo Rojas y Jerónimo Zanné: pensar la nación con Wagner (Argentina y Cataluña -España- a inicios del siglo XX). Journal of Iberian and Latin American Research, 25(1), 22-35. doi: 10.1080/13260219.2019.1671021

» Lafleur, H.R., Provenzano, S.D. y Alonso, F. (2006 [1967]). Las revistas literarias argentinas: 1893-1967. Buenos Aires: Ediciones El 8vo. Loco.

» Louis, A. (2014). Las revistas literarias como objeto de estudio. En En H. 
Ehrlicher, y N. Rißler-Pipka (Eds.). Almacenes de un tiempo en fuga: revistas culturales en la modernidad hispánica (pp. 31-57). Aachen: Shaker Verlag.

»Mansilla, S. (2004). La Asociación Wagneriana de Buenos Aires: instancia de legitimación y consagración musical en la década de 1912-1922. Revista del Instituto de Investigaciones Musicológicas “Carlos Vega”, 18, 19-38.

»Mansilla, S. (Dir.). (2010). Dar la Nota. El rol de la prensa en la historia musical argentina. Buenos Aires: Gourmet Musical Ediciones.

»Pita González, A. (2014). Las revistas culturales como soportes materiales, prácticas sociales y espacios de sociabilidad. En H. Ehrlicher, y N. RißlerPipka (Eds.). Almacenes de un tiempo en fuga: revistas culturales en la modernidad hispánica (pp. 227-245). Aachen: Shaker Verlag.

»Pittaluga, R., López, D. y Ockier, E. (Eds.). (2007). Publicaciones políticas y culturales argentinas (1900-1986). Buenos Aires: CeDInCi.

»Pomian, K. (2010). Historia cultural, historia de los semióforos. Xalapa: Al fin Libre Ediciones Digitales.

» Pujol, S. (2013). Cien años de música argentina. Buenos Aires: Biblos.

»Quesada, E. (1893). El movimiento intelectual argentino: revistas y periódicos (1882). En Reseñas críticas (pp. 119-141). Buenos Aires: Félix Lajouane.

» Rogers, G. (2008). Caras y Caretas: cultura, política y espectáculo en los inicios del siglo XX argentino. La Plata: Editorial de la Universidad Nacional de La Plata.

»Sarlo, B. (1992). Intelectuales y revistas: razones de una práctica. Le discours culturel dans les revues latino-américaines (1940-1970) América-Cahiers du CRICCAL, 9/10, 9-16.

»Suárez Urtubey, P. (2010). 1910: Punto de encuentro entre folklore e indigenismo en la matriz europea de música argentina. En R. Gutiérrez (Coord.). Temas de la Academia. Las artes en torno al Centenario. Estado de la cuestión (1905-1915) (pp. 73-89). Buenos Aires: Academia Nacional de Bellas Artes.

» Tarcus, H. (2007). Catálogo de revistas culturales argentinas (1890-2006). Políticas de la Memoria 6/7. Buenos Aires: CeDInCi.

"Williams, R. (1980). The Bloombsbury Fraction. En Problems in Materialism and Culture. Selected Essays (pp. 148-169). Londres: Verso.

»Williams, R. (2000). Palabras clave. Buenos Aires: Nueva Visión.

\section{Otras fuentes consultadas}

»Actas de la Asociación Wagneriana de Buenos Aires, Libro I, (1912-1917) y Libro II (1917-1923).

》 Revista de la Asociación Wagneriana de Buenos Aires.

»Memoria y Balance de la Asociación Wagneriana de Buenos Aires, 
correspondientes al año 1920. Buenos Aires: Escoffier, Caracciolo y cía. 1921.

» Memoria y Balance de la Asociación Wagneriana de Buenos Aires, correspondientes al año 1922. Buenos Aires: Caracciolo y Plantié. 1923.

\section{Biografía / Biografia / Biography}

\section{María Josefina Irurzun}

Profesora y Licenciada en Historia por la Facultad de Ciencias Humanas de la Universidad Nacional del Centro de la Provincia de Buenos Aires (UNCPBA) y Doctora en Historia por la Universidad Nacional de La Plata. $\mathrm{Su}$ investigación se enfoca en las intersecciones entre historia cultural, música, política e inmigración en Buenos Aires, Argentina (1880-1920). Se ha desempeñado como becaria de grado del Consejo Interuniversitario Nacional (2011-2012) y como becaria doctoral del Consejo Nacional de Investigaciones Científicas y Técnicas, CONICET (2014-2019). Actualmente es becaria posdoctoral del CONICET (2020-2022) y profesora adjunta en la cátedra "Historia de la Cultura" (Departamento de Formación Humanística, Universidad FASTA). Integra proyectos de investigación y extensión, con lugar de trabajo en el Centro de Estudios Sociales de América Latina (CESAL-FCH-UNCPBA). 